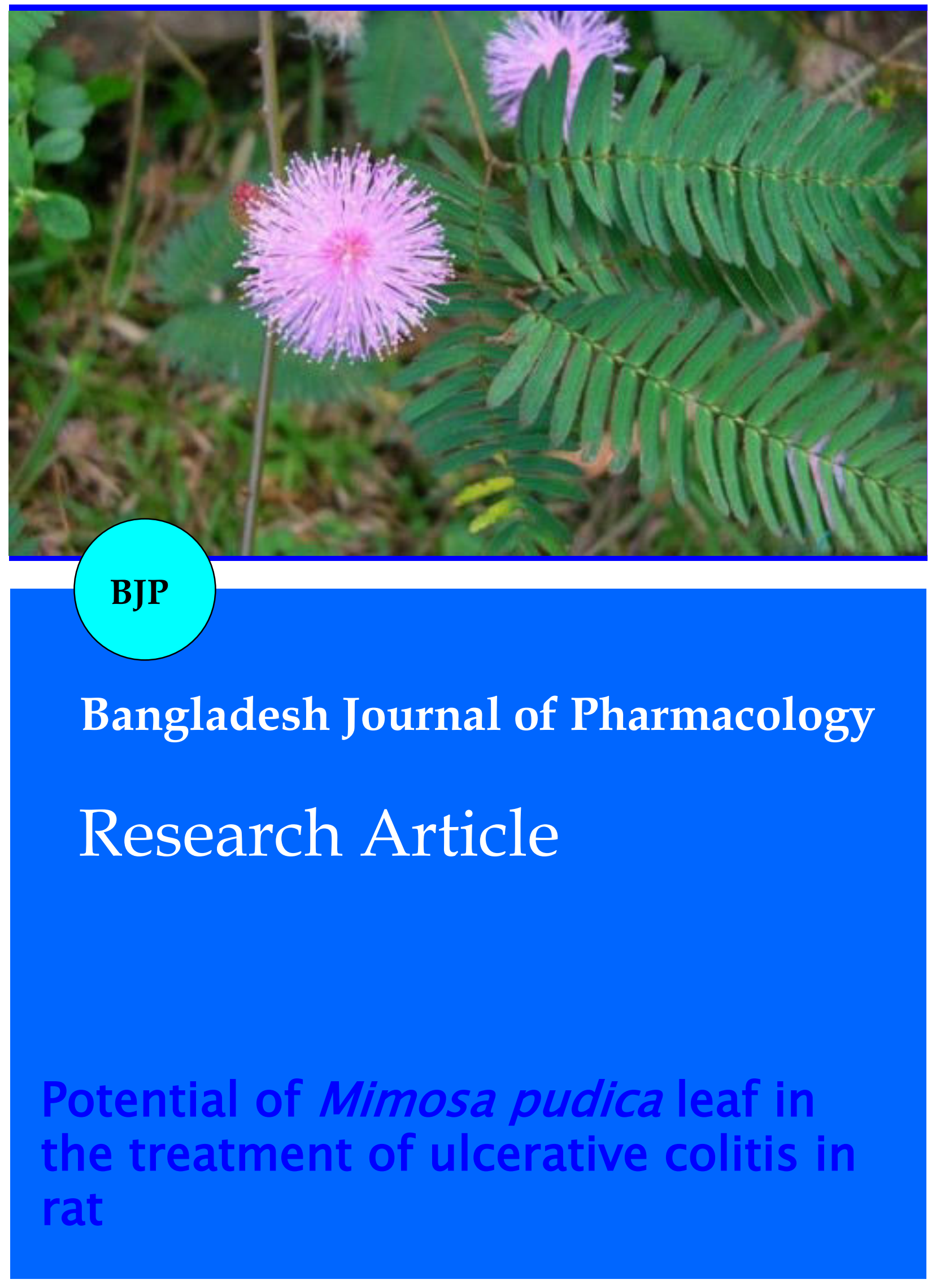




\title{
Potential of Mimosa pudica leaf in the treatment of ulcerative colitis in rat
}

\author{
Bharati Zaware', Ritu Gilhotra ${ }^{1}$ and S. R. Chaudhari ${ }^{2}$ \\ ${ }^{1}$ Department of Pharmacy, Suresh Gyan Vihar University, Jaipur 302017, Rajasthan, India; ${ }^{2}$ Rasiklal M. Dhariwal \\ Institute of Pharmaceutical Education and Research, Chinchwad, Pune 411019, Maharashtra, India.
}

\begin{tabular}{|lr|}
\hline Article Info & \\
\hline Received: & 9 February 2018 \\
Accepted: & 27 July 2018 \\
Available Online: & 14 August 2018 \\
DOI: 10.3329/bjp.v13i3.35648 & \\
& \\
& \\
Cite this article: & \\
Zaware B, Gilhotra R, Chaudhari SR. \\
Potential of Mimosa \\
the treatment of ulcal leaves in \\
rat. Bangladesh J Pharmacol. 2018; 13: \\
241-47.
\end{tabular}

\begin{abstract}
The aim of present investigation was to validate its folk use in the treatment of ulcerative colitis in the rat model. Sprague Dawley rats were divided into nine groups with six animals in each group. The rats received seven days of pretreatment with chloroform, ethyl acetate or ethanolic extract of Mimosa pudica. For induction of ulcerative colitis, rats were administered with $2 \mathrm{~mL}$ of $4 \%$ acetic acid solution intrarectally. Ulcer index, macroscopical study of the colon, myeloperoxidase and malondialdehyde levels in colon tissue and blood, and histopathology of the colon tissue were studied. Intrarectal instillation of acetic acid caused increased ulcer index, colonic myeloperoxidase and malondialdehyde. Pretreatment with M. pudica ethanolic extract (400 $\mathrm{mg} / \mathrm{kg}$ ) significantly lowered the ulcer index, colonic myeloperoxidase and malondialdehyde as compared with the standard drug prednisolone. The present investigation demonstrates that the ethanol extract of $M$. pudica leaf is effective in the treatment of ulcerative colitis.
\end{abstract}

\section{Introduction}

Ulcerative colitis and Crohn's disease are the two major types of inflammatory bowel diseases. Still today the etiology and pathogenesis of both are not confirmed (Fiocchi, 1998). The literature studies suggest that increased production of reactive oxygen species plays a very important role in the destruction of mucosal epithelial layer in inflammatory bowel diseases patient (Hyam et al., 2013; Pullman et al., 1992). The pathophysiology of ulcerative colitis has highlighted the importance of cytokines like tumor necrosis factor- $a$ (TNF- $\alpha$ ), interleukin-1 (IL-1 $\beta$ ), IL-6 and IL-8, which are responsible for the production of reactive oxygen species which activates the oxidative stress-responsive gene that plays an important role in development and maintenance of inflammatory bowel diseases $(\mathrm{Oz}$ et al., 2005).

If the disease is long-term, the risk of developing colon cancer increases (Mclllmurray and Langman, 1975).
Corticosteroid, 5-aminosalicylate, sulfasalazine, methotrexate, prednisolone and immunosuppressive agents (mercaptopurine and azathioprine) are the recent treatment regimens for inflammatory bowel diseases. However, these agents provide partial relief in the patients and these also have several adverse effects and high relapse rate limit their utility in the treatment of inflammatory bowel diseases (Joshi et al., 2005). Therefore, there is a need to develop new medication to treat the inflammatory bowel diseases.

Many herbal formulations conations polyphenolics and flavonoid derivatives show good potential for the treatment of inflammatory bowel diseases (Rahimi et al., 2009). Aloe vera, wheat grass, licorice, slippery elm and curcumin can be used in the treatment of ulcerative colitis (Fei Ke et al., 2012).

Mimosa pudica L. belongs to the family of Fabaceae. The plant, having various polyphenolics and flavonoid derivatives, has been traditionally used for its antidiarrheal, 
antihyperglycemic, anticonvulsant and cytotoxic properties (Vinothapooshan and Sundar, 2010). It has been evaluated for a wide range of activities like antibacterial (Doss et al., 2011), anti-inflammatory (Venkateshwarlu et al., 2011), antifungal (Ibrahim et al., 2014), wound healing (Kokane et al., 2009) and anti-ulcer activity (Elango et al., 2012).

The aim of present investigation is to evaluate the potential of various extracts of $M$. pudica leaf in the treatment of inflammatory bowel diseases like ulcerative colitis in the rat model.

\section{Materials and Methods \\ Plant material}

The leaves of M. pudica were collected from the rural areas of Ahmednagar district, Maharashtra in November 2014. Authentication of the plant was carried out at the Botanical Survey of India, Pune (Voucher specimen number: BBZ01).

\section{Preparation of extract}

A matured leaves of M. pudica were collected, shade dried and made into a coarse powder and then used for extraction. A weighed quantity $(1 \mathrm{~kg})$ of the powder was then subjected to continuous hot extraction in soxhlet apparatus with organic solvents like petroleum ether, chloroform, ethyl acetate, ethanol and water. The extract was concentrated under reused pressure using a rotary evaporator (BUCHI, Rotavapor R-215) at $40-60^{\circ} \mathrm{C}$ until all the solvent had been removed to give an extract sample.

\section{Phytochemical analysis}

The phytochemical study of all the extracts of $M$. pudica was carried out according to the standard methods (Khandelwal, 2007; Kokate, 2005).

\section{Animals}

Female Sprague Dawley female rats (230-250 g) were obtained from the National Institute of Bioscience, Pune, India. Six rats per cage were housed together in the autoclaved polypropylene cages. Cage changing was done once weekly. They were maintained at $24 \pm 1^{\circ}$ C, with a relative humidity of 45 to $65 \%$ and $12: 12$ hours dark/light cycle. The rats were allowed to acclimatize for five days prior to dosing. During this period, animals were observed daily for clinical signs. The animals were fed with standard rodent diet and filtered water ad libitum throughout the experimental protocol, with the exception of overnight fasting before induction of experimental colitis. During this period, the animals had access to filtered water only.

\section{Drugs and chemicals}

Acetic acid, ether, ethanol, ethyl acetate, chloroform, formalin, ether, carbon tetrachloride, ethylene glycol, hydrochloric acid and concentrated sulfuric acid were purchased from Poona Chemical Lab, India. Prednisolone was obtained as a gift sample from Wyeth Pharma Ltd. India.

\section{Toxicity studies}

The acute toxicity study of M. pudica on rats was carried out as per OECD guidelines (Rajendran et al., 2009). The selected doses were 50, 100, 200, 400 and 2,000 mg/ $\mathrm{kg}$ body weight. The animals were observed for toxic symptoms for 72 hours. The methanol extract of $M$. pudica did not produce any toxic symptoms or mortality up to the dose level of 2,000 mg/ $\mathrm{kg}$ body weight in rats, hence the extract was considered to be safe and nontoxic for further pharmacological screening.

\section{Experimental design}

The rats were divided in to nine groups with 6 animals in each group as follows: Group I received saline water ( $2 \mathrm{~mL} / \mathrm{kg} /$ day); Group II received $4 \%$ acetic acid $(1 \mathrm{~mL})$ intrarectally on day 8; Group III received prednisolone ( $2 \mathrm{mg} / \mathrm{kg}$, p.o for 3 days). Prednisolone and acetic acid treatment were started on the same day; Group IV, VI, VIII received 7 days pretreatment with $200 \mathrm{mg} / \mathrm{kg}$ of ethanol, ethyl acetate, chloroform extract of $M$. pudica respectively, p.o. and $1 \mathrm{~mL}$ of $4 \%$ acetic acid solution, intrarectally on day 8. Drug treatment was continued till day 11; Group V, VII and IX received 7 days pretreatment with $400 \mathrm{mg} / \mathrm{kg}$ of ethanol, ethyl acetate, chloroform extract of $M$. pudica respectively, p.o. and 1 $\mathrm{mL}$ of $4 \%$ acetic acid solution, intrarectally on day 8 . Drug treatment was continued till day 11.

Colonic inflammation was induced in overnight fasted rats. After 48 hours of colitis induction blood was withdraw by retro-orbital puncture and animals were sacrificed by cervical dislocation to remove the colon. Five centimeter long piece of the colon was flushed gently with saline, scored for inflammation based on the macroscopic features. Portions of colonic specimens were kept in 10\% formalin for histopathological studies (Millar et al., 1996; Mascolo et al., 1995).

\section{Evaluation of the disease}

The intrarectal instillation of $1 \mathrm{~mL}$ of $4 \%$ acetic acid produced disease in experimental animals, these diseaseinduced experimental animals were evaluated based on its macroscopic characteristics. In this evaluation, pieces of the rat colon $(10 \mathrm{~cm}$ long each) were scored for macroscopic features using a scoring pattern (Morris et al., 1989).

\section{Determination of ulcer index}

The whole alimentary canal was isolated, opened longitudinally, and rinsed with phosphate buffer saline. The ulceration of the opened colon was measured with help of a microscope and the ulcer index was calculated 
using the following formula (Zaware et al., 2011):

Ulcer index $=$ Grade of ulcer in positive control - Grade of ulcer in test/Grade of ulcer in test - Grade of ulcer in normal control $\times 100$

\section{Biochemical analysis of colon for myeloperoxidase and malondialdehyde levels}

Sample preparation: The proximal $5 \mathrm{~cm}$ of the dissected colon specimen was used for biochemical analysis of myeloperoxidase and malondialdehyde levels. The colonic samples were minced and homogenized using a polytron homogenizer. The supernatant was obtained by centrifuging at 3,000 rpm for $20 \mathrm{~min}$ (Murat et al., 2004).

Determination of colonic myeloperoxidase activity: Supernatant sample mixed with citric phosphate buffer having $\mathrm{pH} 5.0$ containing $0.4 \mathrm{mg} / \mathrm{mL}$ O-phenylene diamine and $0.015 \%$ hydrogen peroxide. The change in absorbance measured spectrophotometrically at 492 nm. Test absorbance compared with the standard dilution with horseradish peroxidase. Myeloperoxidase was expressed in $\mathrm{U} / \mathrm{g}$ of wet scrapings (Dighe et al., 2015; Evans et al., 2000).

Determination of malondialdehyde level: The reaction mixture containing $0.1 \mathrm{~mL}$ tissue sample, $0.2 \mathrm{~mL} 8.1 \%$ sodium dodecyl sulfate LR, $1.5 \mathrm{~mL} 2 \%$ acetic acid, and $1.5 \mathrm{~mL} 0.8 \%$ aqueous solution of thiobarbituric acid LR. The mixture $\mathrm{pH}$ was adjusted to 3.5 and the volume was finally made up to $4 \mathrm{~mL}$ with distilled water and 5 $\mathrm{mL}$ of the mixture of $n$-butanol and pyridine $(15 \%)$ was added. The mixture was shaken vigorously. After centrifugation at 4,000 rpm for $10 \mathrm{~min}$, the absorbance of the organic layer was measured spectrophotometrically at $532 \mathrm{~nm}$. Malondialdehyde was expressed as unit per gram of protein (Ganjare et al., 2011).

\section{Histopathological studies}

A representative sample of the colon from each group was washed with saline and the tissue was fixed with $10 \%$ formalin for histopathological studies. It was processed for 24-36 hours and then trimmed at the suitable site and washed under running tap water for 2 hours then the tissue is dehydrated with help alcohol. Then, the tissue was cleaned with xylene and embedded with paraffin wax. $5 \mathrm{~mm}$ thick tissue was deparafinated and immersed in the xylene for $3 \mathrm{~min}$. Sections were rehydrated with alcohol, kept in water for $5 \mathrm{~min}$ and in hematoxylin for $10 \mathrm{~min}$. Dip in $1 \%$ ammonia water was done and instantly washed under running tap water. Add 2 or 3 drops of alcoholic eosin and dehydrated with alcohol. Again slides were cleaned with xylene, stained with Hematoxylin-Eosin and finally examined under a microscope.

\section{Statistical analysis}

The values mean \pm SEM were calculated for each para- meter. Data analysis was performed using GraphPad Prism 5.0 software. All data on biochemical parameters were analyzed using one-way ANOVA; Dunnett's multiple range tests were applied for post hoc analysis. A value of $p<0.05$ was considered to be statistically significant.

\section{Results}

\section{Phytochemical analysis}

The preliminary phytochemical analysis of $M$. pudica extracts revealed the presence of phytoconstituents like alkaloids, carbohydrates, phenols, saponins, flavonoids, glycosides and terpenoids (Table I).

\section{Table I}

\section{Phytochemical test for extract of M. pudica leaf}

\begin{tabular}{|lcccc|}
\hline Test & Chloroform & Ethyl acetate & Ethanol \\
\hline Alkaloids & + & + & + \\
Glycosides & + & + & + \\
Carbohy- & + & + & + \\
drates & & & + \\
Terpenoids & - & - & + \\
Phenols & - & + & + \\
Flavonoids & - & + & + \\
Proteins & - & - & - \\
Saponins & + & - & - \\
Tannins & - & - & - \\
Steroids & + & - & - \\
Note: $(+)$ positive result, $(-)$ negative result & \\
\hline
\end{tabular}

\section{Acetic acid-induced colitis}

As observed from this study, intrarectal instillation of 1 $\mathrm{mL}$ of $4 \%$ acetic acid to the experimental control group caused colonic inflammation when compared to the normal control group. Ethanol extract-treated group showed significant suppressed of inflammatory reaction.

\section{Effect of extract on the macroscopic score}

After intrarectal instillation of $1 \mathrm{~mL}$ of $4 \%$ acetic acid, the colons of the rats were examined macroscopically for signs of hemorrhage, ulceration and inflammations by an independent observer, in a blinded fashion. The mean macroscopical score in control group rats (acetic acid control group) was found to be significantly increased $(\mathrm{p}<0.01)$ as compared to normal group rats. Ethanol extract of M. pudica (200 and $400 \mathrm{mg} / \mathrm{kg}$ ) decreased the macroscopical lesions of colon showed better effect comparable with the standard drug (Table II).

\section{Effect of extract on ulcer protection}


Table II

\begin{tabular}{|c|c|c|}
\hline \multicolumn{3}{|c|}{$\begin{array}{c}\text { Effect of } M \text {. pudica on macroscopic score and ulcer } \\
\text { protection in acetic acid-induced colitis }\end{array}$} \\
\hline Treatment & $\begin{array}{l}\text { Macroscopical } \\
\text { score }\end{array}$ & $\begin{array}{l}\text { Microscopic } \\
\text { ulcer index } \\
(\%)\end{array}$ \\
\hline Normal & $0.0 \pm 0.0$ & 100 \\
\hline Control (4\% acetic acid) & $8.1 \pm 0.4^{\#}$ & 00 \\
\hline Prednisolone (2 mg/kg) & $3.0 \pm 0.4$ & 91 \\
\hline \multicolumn{3}{|l|}{ Extract $(\mathrm{mg} / \mathrm{kg})$} \\
\hline Ethanol (200 ) & $4.6 \pm 0.6^{b}$ & 72 \\
\hline Ethanol (400) & $3.6 \pm 0.4^{c}$ & 75 \\
\hline Ethyl acetate (200) & $5.8 \pm 0.5^{\mathrm{a}}$ & 50 \\
\hline Ethyl acetate (400) & $5.1 \pm 0.4^{\mathrm{a}}$ & 50 \\
\hline Chloroform (200) & $6.8 \pm 0.5$ & 40 \\
\hline Chloroform (400) & $6.5 \pm 0.5$ & 31 \\
\hline \multicolumn{3}{|c|}{$\begin{array}{l}\text { Values expressed as mean } \pm \text { SEM }(n=6) \text { and analyze by ANOVA } \\
\text { followed by Dunnett's test. ap }<0.05 \text {, bp }<0.01, c p<0.001 \text { as compared } \\
\text { to acetic acid control group; } \# p<0.001 \text { as compared to normal group }\end{array}$} \\
\hline
\end{tabular}

Acetic acid control group showed a less protective effect in ulcer index. The seven days pretreatment of ethanol extract of M. pudica (200 and $400 \mathrm{mg} / \mathrm{kg}$ ) showed a better protective effect in ulcer index (Table II).

\section{Effect of extract on colonic myeloperoxidase and} malondialdehyde concentrations

The acetic acid-induced colonic inflammation results increase in myeloperoxidase and malondialdehyde concentrations. Ethanol extract of M. pudica (200 and $400 \mathrm{mg} / \mathrm{kg}$ ) found best in reducing myeloperoxidase and malondialdehyde activities in tissues which were raised by the acetic acid (Table III).

\section{Histopathological study}

Table III

Effect of M. pudica on myeloperoxidase activity and malondialdehyde activity

\begin{tabular}{|lcc|}
\hline Treatment & \multicolumn{2}{c|}{ Activity in tissue (U/g) } \\
\cline { 2 - 3 } & $\begin{array}{c}\text { Myeloperoxi- } \\
\text { dase }\end{array}$ & $\begin{array}{c}\text { Malondialde- } \\
\text { hyde }\end{array}$ \\
\hline Normal & $6.2 \pm 0.5$ & $2.3 \pm 0.3$ \\
Control $(4 \%$ acetic acid) & $15.9 \pm 0.4^{\#}$ & $9.5 \pm 0.4^{\#}$ \\
& & \\
Prednisolone $(2 \mathrm{mg} / \mathrm{kg})$ & $12.4 \pm 0.4$ & $4.8 \pm 0.4$ \\
Extract $(m g / k g)$ & & \\
Ethanol $(200)$ & $13.7 \pm 0.5^{\mathrm{b}}$ & $7.0 \pm 0.5^{\mathrm{b}}$ \\
Ethanol $(400)$ & $13.0 \pm 0.3^{\mathrm{c}}$ & $6.1 \pm 0.45^{\mathrm{c}}$ \\
Ethyl acetate $(200)$ & $14.3 \pm 0.4^{\mathrm{a}}$ & $7.6 \pm 0.5^{\mathrm{a}}$ \\
Ethyl acetate $(400)$ & $14.0 \pm 0.3^{\mathrm{a}^{*}}$ & $7.5 \pm 0.4^{\mathrm{a}}$ \\
Chloroform $(200)$ & $14.8 \pm 0.3$ & $8.5 \pm 0.4$ \\
Chloroform $(400)$ & $15.0 \pm 0.3$ & $8.4 \pm 0.4$
\end{tabular}

Values expressed as mean \pm SEM $(n=6)$ and analyze by ANOVA followed by Dunnett's test. a $\mathrm{p}<0.05,{ }^{\mathrm{b}} \mathrm{p}<0.01,{ }^{\mathrm{c}} \mathrm{p}<0.001$ as compared to acetic acid control group; $" \mathrm{p}<0.001$ as compared to normal group

Histopathological observation ulcerated parts of the colon of the rat treated with $4 \%$ acetic acid showed transmural necrosis, edema, ulceration, hemorrhages, hyperemia, and cellular infiltration in the colon of rat (Figure 1). The 7 days pretreatment of ethanol extract of M. pudica $(400 \mathrm{mg} / \mathrm{kg})$ found to be preventive progression of colitis. The preventive effect observed by morphologically as well as histopathological studies (Table IV).

\section{Discussion}

Acetic acid-induced colitis in laboratory rats model is

Table IV

\section{Histopathological observations after the treatment with extracts of M.pudica}

\begin{tabular}{|c|c|c|c|c|c|c|}
\hline Treatment & Ulceration & Hyperemia & Necrosis & Edema & Cellular infiltration & Goblet-cell hyperplasia \\
\hline Normal & 0 & 0 & 0 & 0 & 0 & 0 \\
\hline (4\% acetic acid) & ++++ & ++++ & ++++ & ++++ & ++++ & ++++ \\
\hline Prednisolone (2 mg/kg) & + & ++ & + & + & + & ++ \\
\hline \multicolumn{7}{|l|}{ Extract $(m g / k g)$} \\
\hline Ethanol (200) & ++ & ++ & +++ & ++ & ++ & +++ \\
\hline Ethanol (400) & ++ & + & + & + & ++ & ++ \\
\hline Ethyl acetate (200) & +++ & ++ & +++ & ++ & ++ & +++ \\
\hline Ethyl acetate (400) & ++ & ++ & +++ & +++ & ++ & +++ \\
\hline Chloroform (200) & +++ & ++ & +++ & +++ & ++ & +++ \\
\hline Chloroform (400) & ++ & +++ & +++ & ++ & +++ & +++ \\
\hline
\end{tabular}

(0): no abnormality detected; (+): damage/ active changes up to less than $25 \%$; $(++)$ : damage/active changes up to less than $50 \%$; $(+++)$ : damage/active changes up to less $75 \% ;(++++)$ : damage/ active changes up to more than $75 \%$ 


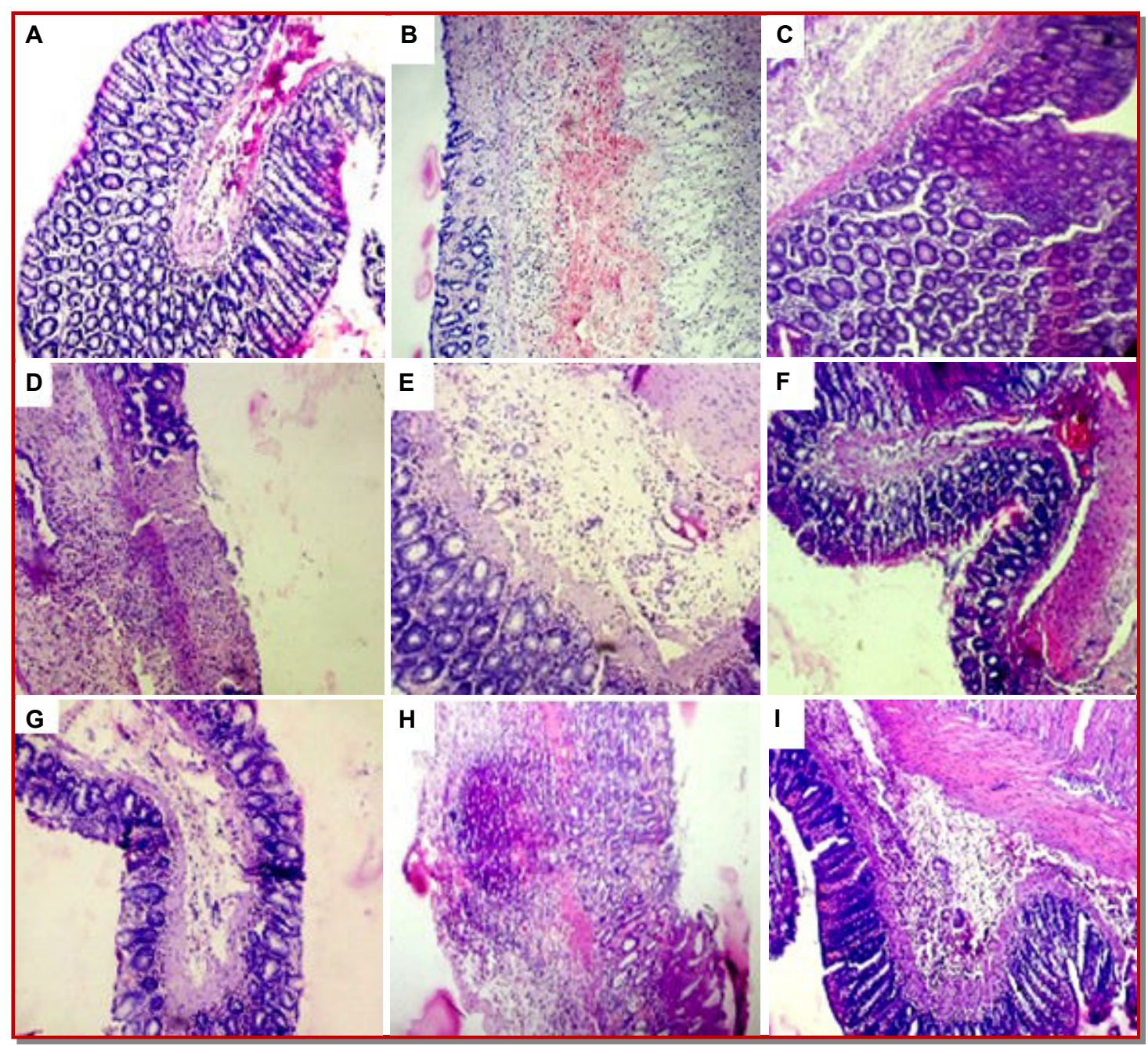

Figure 3: Photomicrographs of sections of colons from rats stained with $\mathrm{H}$ and $\mathrm{E}$.

Histopathological observations of colon tissue after the treatment with M. pudica leave extract. (A) Normal; (B) Control (4\% acetic acid); (C) Prednisolone (2 mg/kg); (D) Ethanol extract (200 mg/kg); (E) Ethanol extract (400 mg/kg); (F) Ethyl acetate (200 mg/kg); (G) Ethyl acetate (400 mg/ $\mathrm{kg})$; (H) Chloroform (200 mg/kg); (I) Chloroform (400 mg/kg)

one of the most commonly used experimental models while screening drugs active against ulcerative colitis. The intrarectal administration of acetic acid produces inflammation appears to involve the entry of the protonated form of the acid within the intracellular space and causes intracellular acidification resulting in epithelial damage and localized erosion of the colonic mucosa leading to hemorrhages and severe localized inflammation. The inflammatory response by acetic acid activates the cyclooxygenase enzymes and lipooxygenase enzymes pathways which results generation of inflammatory mediators likes prostaglandin and leukotrienes (Jagtap et al., 2004; Nakhai et al., 2007; Macpherson and Pfeiffer, 1978).

Mucosal immune system is the main effectors of intestinal inflammation and injury, with cytokines playing a central role in modulating inflammation (Ardizzone and Bianchi, 2005; Nakamura et al., 2006).
Increased levels of both TNF-a and $\mathrm{PGE}_{2}$, in this work caused epithelial cell necrosis, edema and neutrophil infiltration, as proved by the histopathological study.

Ethanolic extract of M. pudica has possessed a significant protective activity against experimental colitis in rats, as indicated by macroscopic, microscopic observations ulcer index and biochemical evaluations.

Ulcer index was quantitatively determined. Pre-treatment of ethanol extract showed a better protective effect in ulcer index than other extracts comparable to standard drug.

Myeloperoxidase is a peroxidase enzyme mostly found in neutrophil granulocytes. It is a good marker of tissue injury, inflammation and neutrophil infiltration. Acetic acid raised the levels of colonic myeloperoxidase, indicating infiltration of neutrophils and perturbation of the inflammatory system, it indicates that neutrophil 
accumulation contributes to the colitis induce oxidative injury. (Krawisz et al., 1984). Pretreatment with ethanol extract of $M$. pudica leaves ameliorated neutrophil infiltration as evidenced by inhibition of colon myeloperoxidase level and development of histological features (Joshi et al., 2011; Shiratora et al., 1989).

Malondialdehyde is a good indicator of lipid peroxidation (Zama et al., 2007), which is found to be increased in colonic tissue of the rats treated with acetic acid. Elevated lipid peroxidation can initiate vicious cycles that produce reactive metabolites, which weaken cellular anti-oxidants and help the development of more inflammation. Pretreatment of ethanol extract of $M$. pudica increase colonic oxidative balance in rats on colitis since it was able to reduce the malondialdehyde level significantly (Ohkawa et al., 1979). The M. pudica contains phytochemicals like flavonoid, alkaloids, glycosides and phenolic compounds. The present results may lead pharmacological support to folkloric, ethnomedical uses of the plant in the management of inflammatory gastrointestinal tract disorders. Flavonoid and phenolic substances found in green plants which possess anti-oxidant and anti-inflammatory property (Sharma et al., 2011).

\section{Conclusion}

M. pudica leaves ethanol extract possesses potent activity against various pathological changes caused by administration of acetic acid. The flavonoid derivatives present in M. pudica may possess anti-oxidant as well as anti-inflammatory potential against acetic acid-induced experimental colitis by inhibition of release of oxidoinflammatory mediators like myeloperoxidase and malondialdehyde.

\section{Ethical Issue}

All procedures of the proposed study was in accordance with the standard operating procedures of PRADO (Preclinical Research and Development Organization laboratory, Pune where the activity performed) and the guidelines provided by the Committee for the Purpose of Control and Supervision of Experiments on Animals (CPCSEA) as published in The Gazette of India, December 15, 1998. Prior approval of the Institutional Animal Ethics Committee (IAEC) was obtained before initiation of the study (IAEC-15-010).

\section{References}

Ardizzone S, Bianchi PG. Biologic therapy for inflammatory bowel disease. Drugs 2005; 65: 2253-86.

Dighe SB, Kuchekar BS, Wankhede SB. Potential of Oxalis Corniculata Linn in the treatment of ulcerative colitis. Int J Pharma Bio Sci. 2015; 6: 117-25.
Doss A, Vijayasanthi M, Parivuguna V, Anand SP. Evaluation of antibacterial properties of ethanol and flavonoids from Mimosa Pudica Linn. and Panicum Maximum Jacq. Plant Sci Feed. 2011; 1: 39-44.

Elango V, Carolin O, Raghu PS. Antiulcer activity of the leaf ethanolic extract of Mimosa pudica in rats. J Drugs Med. 2012; 4: $34-40$.

Evans M, Laszlo R, Brendan J, Whitlle R. Site specific lesion formation inflammation and inducible nitric oxide synthase expression by indomethacin in the rat intestine. Eur J Pharm. 2000; 388: 281-85.

Fei Ke, Yadav PK, Liuzhan Ju. Herbal medicine in the treatment of ulcerative colitis. Saudi J Gastroenterol. 2012; 18: 310.

Fiocchi C. Inflammatory bowel disease: Etiology and pathogenesis. Gastroenterology 1998; 115: 182-205.

Ganjare AB, Nirmal SA, Patil AN. Use of apigenin from Cordia dichotoma in the treatment of colitis. Fitoterapia 2011; 82: 1052 -56 .

Hyam SR, Jang SE, Jeong JJ, Joh EH, Han MJ, Kim DH. Echinocystic acid, a metabolite of lancemaside A, inhibits TNBS-induced colitis in mice. Int Immunopharmacol. 2013; 15: $433-41$.

Ibrahim DI, Muhammad I, Kanoma AI, Shehu K, Aliero AA, Aliyu RU. Antifungal screening of Mimosa pudica plant extracts against phytopathogenic fungi. Open Sci J Biosci Bioeng. 2014; 1: 1-12.

Jagtap AG, Shirke SS, Phadke AS. Effect of polyherbal formulation on experimental models of inflammatory bowel disease. J Ethnopharmacol. 2004; 90: 195-204

Joshi R, Kumar S, Unnikrishnan M, Mukherjee T. Free radical scavenging reactions of sulfasalazine, 5-aminosalicylic acid and sulfapyridine: Mechanistic aspects and anti-oxidant activity. Free Radic Res. 2005; 39: 1163-72.

Joshi SV, Vyas BA, Shah PD, Shah DR, Shah SA, Gandhi TR. Protective effect of aqueous extract of Oroxylum indicum Linn. (root bark) against DNBS-induced colitis in rats. Indian J Pharmacol. 2011; 43: 656-61.

Khandelwal KR. Practical pharmacognosy: Techniques and experiments. 8th ed. Pune, Nirali Prakashan, 2007, pp 149-53.

Kokane DD, More RY, Kale MB, Nehete MN, Mehendale PC, Gadgoli $\mathrm{CH}$. Evaluation of wound healing activity of root of Mimosa pudica. J Ethnopharmacol. 2009; 124: 311-15.

Kokate CK. Practical pharmacognosy, New Delhi, Vallabh Prakashan, 2005, pp 107-08, 115-20, 122-23.

Krawisz JE, Sharon P, Stenson WE. Quantitative assay for acute intestinal inflammation based on myeloperoxidase activity: Assessment of inflammation in rat and hamster models. Gastroenterology 1984; 87: 1344-50.

Macpherson B, Pfeiffer C. Experimental production of diffuse colitis in rats. Digestion 1978; 17: 135-50.

Mascolo N, Izzo A, Autore G, Maiello F, Carlo G, Capasso F. Acetic acid- induced colitis in normal and essential fatty acid deficient rats. J Pharmacol Exp Ther. 1995; 272: 469-75. 
Mclllmurray MB, Langman MJ. Large bowel cancer: Causation and management. Gut. 1975; 16: 815-20.

Millar AD, Rampton DS, Chander CL. Evaluating the antioxidant potential of new treatments for inflammatory bowel disease using a rat model of colitis. Gut 1996; 39: 407-15.

Morris GP, Beck PL, Herridge MS, Depew WT, Szewczuk MR, Wallace JL. Hapten-induced model of chronic inflammation and ulceration in the rat colon. Gastroenterology 1989; 96: 795-803.

Murat Z, Mustafa K, Erhan A, Ozgur F, Murat A, Gokhan I. The comparative effects of calcium channel blockers in an experimental colitis model in rats. Turk J Gastroenterol. 2004; 15: 243-49.

Nakamura K, Honda K, Mizutani T, Akiho H, Harada N. Novel strategies for the treatment of inflammatory bowel disease: Selective inhibition of cytokines and adhesion molecules. World J Gastroenterol. 2006; 12: 4628-35.

Nakhai LA, Mohammadirad A, Yasa N, Minaie B, Nikfar S, Ghazanfari G. Benefits of Zataria multiflora Boiss in experimental model of mouse inflammatory bowel disease. Evid Based Complement Alternat Med. 2007; 4: 43-50.

Ohkawa H, Ohishi N, Yagi K. Assay for lipid peroxidase in animal tissues by thiobarbituric acid reaction. Ann Biochem. 1979; 95: 351-58.

Oz HS, Chen TS, McClain CJ, de Villiers WJ. Anti-oxidants as novel therapy in a murine model of colitis. J Nutr Biochem. 2005; 16: 297-304.

Pullman WE, Elsbury S, Kobayashi M, Hapel AJ, Doe WF. Enhanced mucosal cytokine production in inflammatory bowel disease. Gastroenterology 1992; 102: 529-37.
Rahimi R, Mozaffari S, Abdollahi M. On the use of herbal medicines in management of inflammatory bowel diseases: A systematic review of animal and human studies. Dig Dis Sci. 2009; 54: 471-80.

Rajendran R, Hemalatha S, Akasakalai K, Madhukrishna $\mathrm{CH}_{\text {, }}$ Bavan S, Sundaram RM, Hepatoprotective activity of Mimosa pudica leaves against carbon tetrachloride induced toxicity. J Nat Prod. 2009; 2: 116-22.

Sharma V, Rajani GP. Evaluation of Caesalpinia pulcherrima Linn. for anti-inflammatory and antiulcer activities. Ind J Pharmacol. 2011; 43: 168-71.

Shiratora Y, Aoki S, Takada H, Kiriyama H, Ohto K, Hai K, Teraoka H, Matano S, Matsumoto K, Kamii K. Oxygenderived free radical generating capacity of polymorphonuclear cells in patients with ulcerative colitis. Digestion 1989; 44: 163-71.

Venkateshwarlu G, Kanakam VB, Sravan PM, Jimmidi PS, Ramchander T. Effects of anti-Inflammatory activity of Mimosa pudica. Asian J Pharm Res. 2011; 1: 69-71.

Vinothapooshan G, Sundar K. Anti-ulcer activity of Mimosa pudica leaves against gastric ulcer in rats. Res J Pharmaceut Bio Chem Sci. 2010; 1: 606-14.

Zama D, Meraihi Z, Tebibel S, Benayssa W, Benayache F, Benayache S. Chlorpyrifos-induced oxidative stress and tissue damage in the liver, kidney, brain and fetus in pregnant rats: The protective role of the butanolic extract of Paronychia argentea L. Ind J Pharmacol. 2007; 39: 145-50.

Zaware BB, Nirmal SA, Baheti DG, Patil AN, Mandal SC. Potential of Vitex negundo roots in the treatment of ulcerative colitis in mice. Pharmaceutical Bio. 2011; 49: 1-5.

Author Info
Bharati Zaware (Principal contact)
e-mail: bharatipadwal123@gmail.com 